\title{
Use of modern construction machinery in the construction
}

\author{
Sergey Prochorov ${ }^{1^{*}}$ \\ ${ }^{1}$ Vladimir State University named after Alexander and Nikolay Stoletovs, Gorky st. 87, Vladimir, \\ 600000, Russia
}

\begin{abstract}
In the presented article there will be discussed measures which allow to lower expenses for the maintenance of the machinery and which contribute to the increase of energy saving in general. To achieve these goals, it is proposed to apply modern methods of organizing and operation works, to use high-tech construction equipment, and also to form an optimal mechanization complex of building and construction works. The optimization criterion is the cost of work. When determining costs for the operation of construction machinery at the site, we take into account their energy efficiency, compare the options and manage the most efficient fleet of construction equipment. In the course of meeting the task, there were drawn conclusions which demonstrate that an integrated approach to the formation of machinery parks on the construction site allows to use the available resources more rationally, in order to improve the environmental component and improve the quality of construction work.
\end{abstract}

\section{Introduction}

The construction industry at the current stage is going through difficult times. The cost of machine and mechanisms operations in the production of construction and installation works takes a large part of the total cost for the construction of the facility. The present article solves the problem of reducing the costs of technical equipment fleet operation and increasing the level of construction energy saving in general. To achieve these goals, it is proposed to apply modern methods of organizing and operation works, to use high-tech construction equipment, and also to form an optimal mechanization complex of building and construction works. The optimization criterion is the cost of operation and the productivity of the set.

In the course of solving the task, there were drawn the conclusions which showed that the energy audit of the works mechanization in comparison with productivity, cost price and energy costs allows more fully to approach to the formation of car parks in order to improve the environmental component and the quality of construction and installation works.

The solution of resource-saving issues is one of the most important directions in the modern economy and industry. [1,2] A considerable amount of energy resources are consumed during the construction and installation works, aimed to build new object, and to cover the household maintenance of the builders involved in the process. A fairly significant

\footnotetext{
*Corresponding author: oc204@bk.ru
} 
part of these inputs is taken up by the construction machines and mechanisms operations. Manufacturers of modern construction equipment have long been producing machines with hybrid plants that can not only reduce fuel costs, but to reduce noise and releases into the environment, while working. [3,4] One of the most effective means of energy saving of the construction machines with hydraulic drive equipment, are recuperative systems with an energy storage device $[5,6]$. In the hydraulic excavators "Komatsu HB215LC-1", "Cat 336E $\mathrm{H}$ " the kinetic energy is restored and accumulated when the rotating superstructure brakes. The accumulated energy from the condenser or nitrogen charged accumulator can then be used as an auxiliary to power the electrical and hydraulic installations of the machine.

Another example of a constructive approach to energy conservation is the conversion of kinetic energy from deceleration to electric current. The regenerative braking system allows you to stop the machine without using conventional brakes, thereby increasing their life. In addition, the hybrid system saves up to $45 \%$ of the fuel. [7.8]

The use of a variable-frequency electric drive in building cranes with a regenerative module instead of relay-contactor panels, allows to significantly reduce power consumption. The use of regenerative modules that replace resistors in drives with continuous operation in the generator mode, or having a large braking power, such as for lifting and inerting mechanisms, allows to recover some of the energy from braking of the electric drive to the power supply network. [9]

In addition to the use of modern samples of construction equipment, the energy efficiency of the construction equipment can be achieved through the implementation of organizational and technological measures. 2D and 3D automatic control systems and positioning are widely used in preparatory works, earthworks and landscaping. [10,11] The use of these systems allows to significantly reduce the costs and time for performance operations. The software of the "VirtualSite Solutions" company allows you to monitor performance and technical condition, as well as to quickly identify the underutilized machines in real time. [12]

Another area of the energy consumption reduction and energy saving is the use of modern diagnostic complexes and organizational measures aimed to maintain the equipment in good working order. [13,14,15]

When choosing sets of mechanization for the production of construction and installation works, as a rule, the cars are imposed by the following requirements:

1. High efficiency and reliability;

2. Availability of cars in the shortest possible time and in the required quantity;

3. The minimum, reasonable cost of machine hours.

\section{Methods}

Mathematical modeling was taken as the basis of the research methodology. In the process of solving the problem of completing the park of construction machinery, there is a need to build a multi-level hierarchical system of interrelated mathematical models. With such a decision, it is possible to take into account the main features and the interrelations arising in the design, and at the same time it allows the study of individual models.

The total costs for the maintenance of construction equipment, according to their energy efficiency, were taken as optimization criteria:

$$
Z_{\mathrm{ud}}=s *\left(1+\frac{F}{V} * \frac{r}{100}\right)+\sum_{i=1}^{n} \frac{R_{i}}{W_{i}}
$$

where $s$ - cost of work, rub; $F$ - average annual cost of fixed production assets and working capital, rubles; $V$-annual turnover of the construction organization, rub; $\mathrm{r}$ - internal rate of return on capital; $R_{i}$ - annual costs for maintenance and operation of the i-th machine, rub; $W_{i}$ - estimated remaining life of the $i$-th machine, year; $n$-is the number of machines of this type, pcs 
The average performance of the machine is determined by:

$$
\overline{\Pi_{i}}=\frac{\sum_{j=1}^{n} \Pi_{i j} * \mathrm{~K}_{t i} * K_{v i} * K_{r i}}{n}
$$

where $\Pi_{i j}$ - productivity of $\mathrm{i}$-th machine at $\mathrm{j}$-th site; $\mathrm{K}_{t i}$ - coefficient, taking into account the effect of temperature on the rise in the cost of works; $K_{v i}$ - coefficient that takes into account the influence of age of the equipment on the cost of operation; $K_{r i}$ - coefficient that takes into account the impact of operating conditions and work structure

Annual costs for the maintenance and operation of machines are determined by the formula:

$$
R_{\mathrm{i}}=S_{\mathrm{t}}+S_{\mathrm{d}}+S_{\mathrm{n}}
$$

where $S_{t}$ - the cost of transporting the machine to the place of work, rub; $S_{d}$ - costs for maintenance and repair of the machine, rub; $S_{n}$ - energy costs, rub.

The costs of maintenance and repair were determined by taking into account the probabilistic coefficients which depends on the term of operation and work conditions of the equipment. The influence of the above criterias was determined on the basis of statistical processing of reliability and productivity indicators of machinery in construction organizations [16]

$$
S_{\mathrm{d}}=S_{\mathrm{s}} * y_{\mathrm{ti}} * y_{\mathrm{vi}} * y_{\mathrm{ri}}
$$

where $S_{s}$ - average costs for maintenance and repair of machines of this type, rub; $y_{t i \text {-coefficient, }}$ taking into account the influence of temperature on the rise in the cost of work; $y_{v i}$ - coefficient, taking into account the influence of age of technology on the cost of operation; $y_{r i}$ - coefficient, taking into account the influence of operating conditions and the structure of work.

The coefficient that takes into account the influence of temperature on the rise of construction and installation works cost, is based on calculation of the dependence between the change in the total costs of the machine's work performing, and the natural and climatic conditions. is to compare repair and maintenance costs with the temperature and time of the year.

The coefficient that takes into account the impact of the equipment's lifetime is determined on the basis of the flow of failures, and on the time while equipment is in repair and maintenance, as well as on financial losses as a result of a sudden failure of equipment at the facility.

The coefficient that takes into account the structure of works, was determined on the basis of the construction machine's workload percentage, while it performs the specified amount of work, as well as the speed of attachments or units changing. In this criterion, the best indicators are shown by multifunctional machines with a high level of computerization and a possibility to choose the parameters for the equipment's operation.

Energy costs for the perform operations of a construction equipment set, are determined by the formula:

$$
\mathrm{S}_{\mathrm{n}}=\sum_{\mathrm{i}=1}^{\mathrm{n}} \mathrm{q}_{\mathrm{i}}^{*} \mathrm{y}_{\mathrm{i}}{ }^{*} \mathrm{l}_{\mathrm{n}}
$$

where $q_{i}$ - is the rate of energy consumption; $y_{i}$ is the coefficient of the power equipment load; $l_{n}-$ weighted average cost of energy 
According to the result of energy audit in the course of work, the load coefficient can be determined depending on the soil group, the conditions of production (temperature and humidity conditions, water saturation of soils, etc.). At the initial stage, it can be taken equal to 1 , then the calculation will be made only on the basis of petrol, oil and lubricants consumption standards.

When calculating this indicator, it is necessary to consider the long-term prospects of using modern models of energy-saving equipment, as well as the possibility of its modernization.

The selection of the optimal construction equipment park structure, is made basing on the projected workload, after the determination of the coefficients for each type of machine. Existing software tools and techniques are used, to solve the transport problem. Meanwhile, during the selection process it's possible to impose restrictions(cost, productivity, energy costs) and get the most optimal sets.

In addition to the economic effect, the use of energy-efficient sets makes it possible to improve the environmental component of construction and installation works, and to preserve the environment of the adjacent territories.

The calculation input determines the standard mean square deviation of the given costs, as well as a comparison of the results between implemented planned measures, aimed to improve organizational and technological processes, and those which already exists in the organization.

Basing on the comparison of different variants of machine parks and the works production methods, it is possible to complete and to realize operational management of the construction organization.

\section{Results}

In the analysis of machine parks structure in the construction industry of the Russian Federation, it can be noted that the share of construction organizations which are not fully equipped with machines and mechanisms, is steadily growing (Fig. 1). This is especially noticeable in the Moscow region.

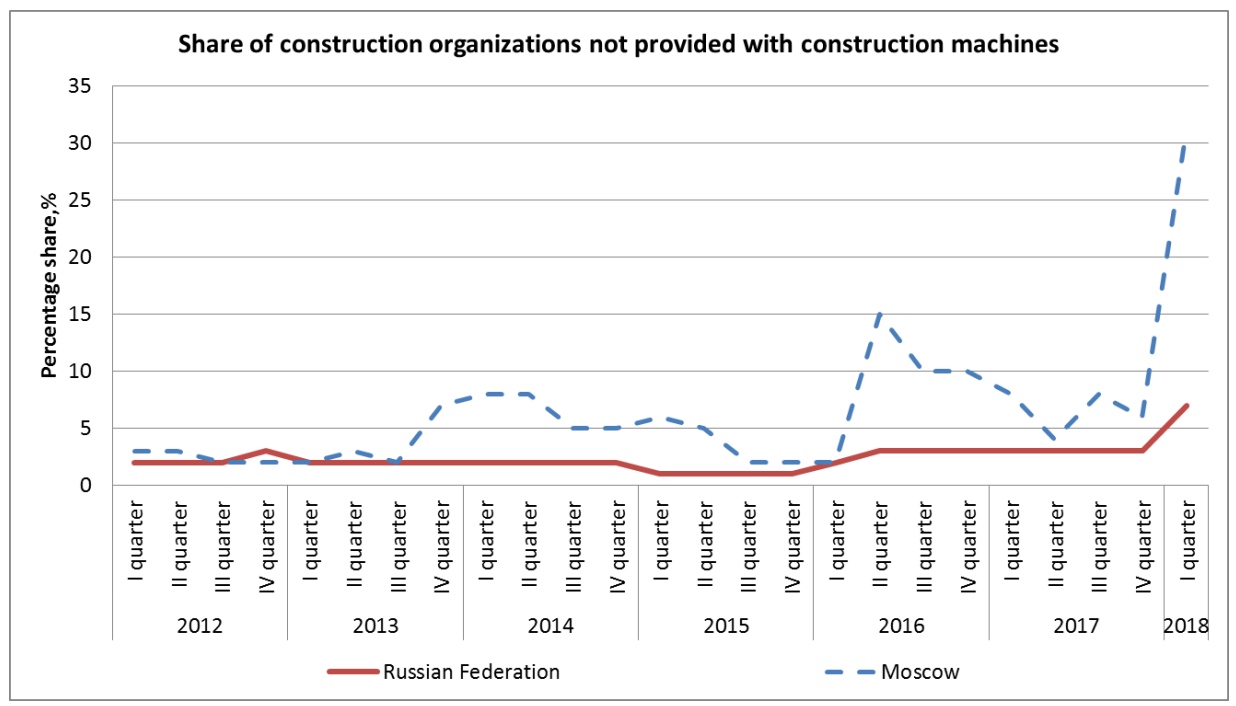

Fig. 1. The share of construction organizations which are not provided with construction machinery 
In Figure 1. it can be seen that construction organizations are in dire need of renovation of construction machines. The current situation does not allow us to adequately compete in the construction market and does not provide an opportunity to modernize the technology of construction and installation works.

As a result of the structure and magnitude analysis of the financial costs for the performance of work, it was revealed that:

- the level of automatic positioning use in the of excavation production, does not exceed $2 \%$.

- costs for maintenance and repair of construction equipment are about $40 \%$ of the machine-hour cost price.

- the amount of energy costs, which provide the work of the machines and mechanisms, as well as the performance of technological operations, amounts to $20 \%$ of the total costs.

In contrast to works examining the durability of construction and road machines based on mathematical modeling and optimal system resources [17], the presented studies have shown the need of more careful consideration of the factors, which affect the energy efficiency and functionality of construction equipment.

After the leading construction organizations of the region completed the fleet of construction equipment in the proposed way, the share of electricity costs decreased to $15 \%$, for maintenance and repairs to $25 \%$. The projected percentage increase in the production of equipment will be $10 \%$.

The economic effect of the proposed solution is achieved by solving the following issues:

- quantitative optimization of the fleet of vehicles, based on the required amount of work and the use of multifunctional machines;

- a qualitative renewal of the fleet of equipment due to the released units of equipment;

- increase in technical level readiness, depending on various factors;

- reduction of the vehicles idle time during repair and maintenance;

- reduction in the cost of work due to the use of energy-saving equipment and technologies. (Fig. 2).

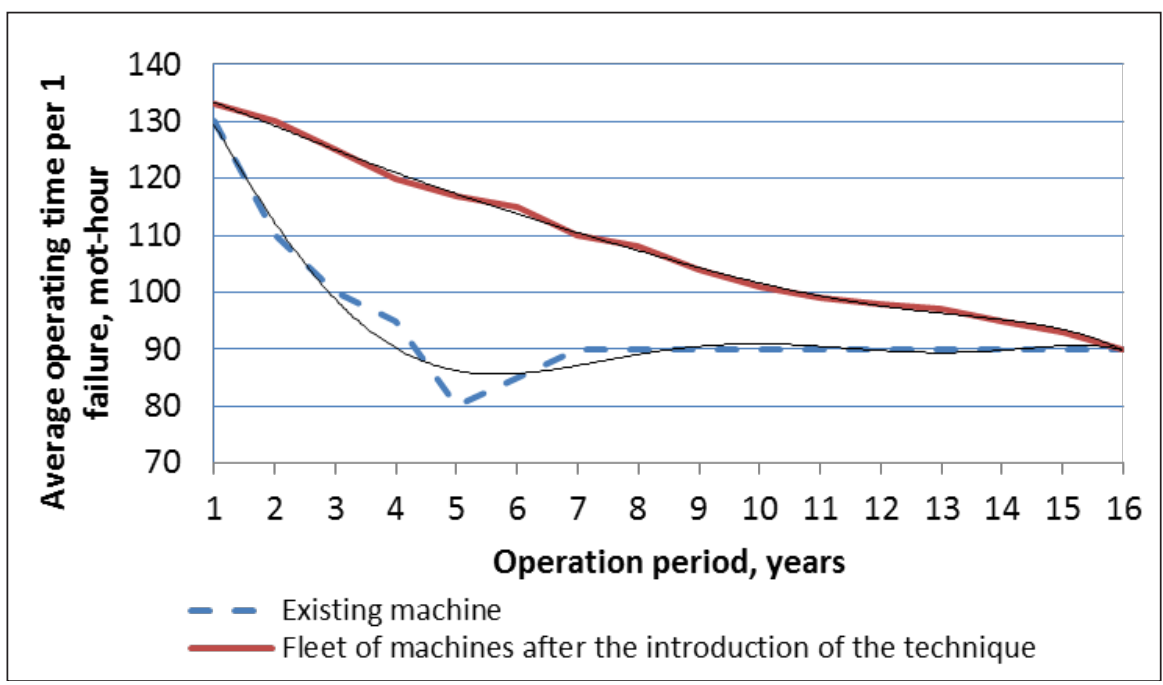

Fig. 2. Distribution of failures in excavators 


\section{Conclusions}

The proposed methodology allows to minimize losses from downtime due to a lack of work front, as well as downtime caused by failures under the influence of various factors. This is achieved through a more careful consideration of each individual impact factor per unit of equipment. The use of foreign experience in the field of construction and installation works automation, and the implementation of new systems for the monitoring of technical condition, energy and resource saving, will, on the one hand, prolong the life of existing equipment parks, and on the other, rejuvenate and accumulate experience in the use of energy-efficient technologies.

Thanks to investments in local engineering and capital construction, it is possible to reduce import dependence and to increase the competitiveness of domestic companies.

The main advantages of the methodology are:

1. Complex evaluation of vehicle sets, organizational and technological measures, allows to evaluate and select equipment according to priority indicators.

2. The use of modern technologies and vehicles, can significantly increase the competitiveness of construction organizations.

3 . The use of this methodology allows to perform an energy audit of the mechanization operations, with a of productivity, cost and energy costs comparison.

\section{References}

1. 1. A. G. Gaglia, A. G. Tsikaloudaki, C. M. Laskos, E. N. Dialynas, A. A. Argiriou The case of Greece. Energy and Buildings 155 (2017)

2. R. Galvin, M. Sunikka-Blank Building and Environment 118 (2017).

3. V. F. Shcherbakov Building and road machines 9 (2008)

4. M. Goydo Hydraulics, pneumatics, drives ( HPD) 2 (2013)

5. T. Lin, Q. Chen, H. Ren, W. Huang, Q. Chen, S. Fu Proceedings of the Inst. of Mech. Engin., Part C: Jour. of Mech. Engin. Sci. 22 (2017)

6. L. Ge, X. Zhang, L.Quan, C.Wang, L.Wu Journal of Mechanical Engineering 16 (2017)

7. V. N. Kuznetsova, V. V. Savinkin Herald of Siberian State Automobile and Road Academy 5 (2013)

8. P. V. Shcherbachev, S. Ye. Semenov Science and education of Bauman MSTU 10 (2012)

9. 9. S. Spirk Adaptive Regelung aktiver Fahrwerke (Herstellung Bachelor+Master Publishing? Ein Imprint der Diplomica Verlag GmbH, Hamburg,2012)

10. N. Ahmed, A. J. W. Hong, H. Ku, S. Moon, S. Moon, ISARC 2017 - Proc. of the 34th Int. Symposium on Automation and Robotics in Construction (2017)

11. Y. Fang, J. Chen, Y. K. Cho, P. Zhang ISARC 2016 - 33rd Int. Symposium on Automation and Robotics in Construction (2016)

12. M. Rechmedin CTT: Construction Equipment and Technologies. 3(119) (2016)

13. URL: https://construction.trimble.com/products-and-solutions/visionlink (Accessed 21.11.2017)

14. S. F. Golovin Ensuring Machine and Tractor Aggregates Operability 2016 IOP Conference Series: Materials Science and Engineering. 48 (2016)

15. I. N. Kravchenko, A. V. Myasnikov, et.al Construction and road machines. 1 (2013)

16. S. V. Prokhorov Building and road machines. 6 (2015) 